
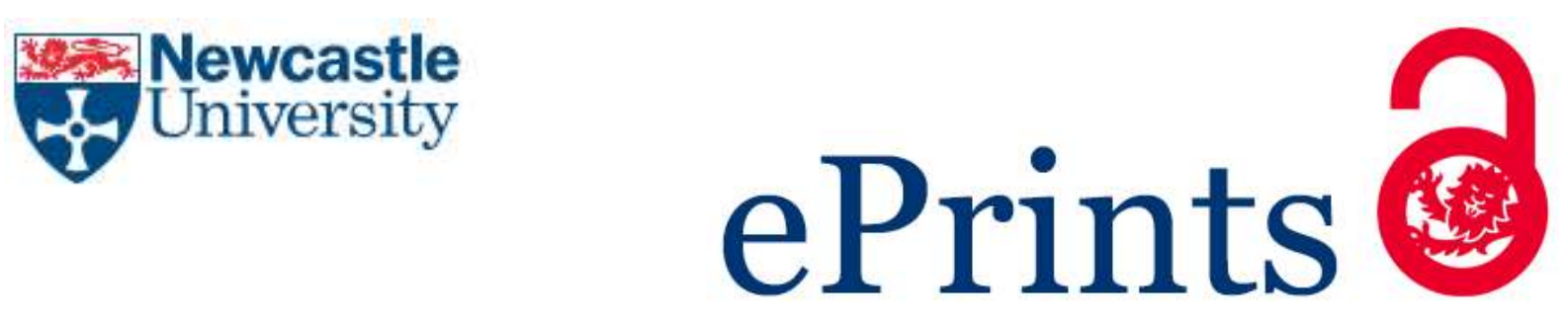

Smith-Jackson K, Denton H, Cook K, Pickering MC, Cook TH, Marchbank KJ. $\underline{\text { A }}$ novel C3 gain of function mouse model of atypical haemolytic uraemic syndrome. In: 26th International Complement Workshop (XXVI ICW). 2016, Kanazawa, Japan: Elsevier GmbH - Urban und Fischer.

Copyright:

(C) 2015. This manuscript version is made available under the CC-BY-NC-ND 4.0 license

DOI link to article:

http://dx.doi.org/10.1016/j.imbio.2016.06.028

Date deposited:

$11 / 04 / 2017$

Embargo release date:

11 August 2017

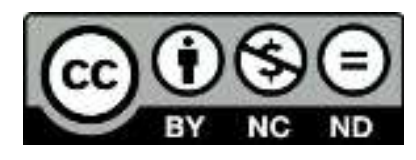

This work is licensed under a

Creative Commons Attribution-NonCommercial-NoDerivatives 4.0 International licence 


\section{A Novel C3 Gain of Function Mouse Model of atypical Haemolytic Uraemic Syndrome.}

Kate Smith-Jackson ${ }^{1}$; Harriet Denton ${ }^{1}$; Katie Cook ${ }^{1}$; Mathew C. Pickering ${ }^{2}$; Terrence H. Cook ${ }^{2}$; Kevin J. $\underline{\text { Marchbank }^{1}}$

${ }^{1}$ Institute of Cellular Medicine, Newcastle University

${ }^{2}$ Imperial College, London

Complement $(\mathrm{C})$ is key to host homeostasis and $\mathrm{C}$ dysfunction can manifest in disease. For example, atypical haemolytic uraemic syndrome (aHUS), a rare kidney disease, can arise from impaired regulation or gain of function changes in the alternative pathway. Indeed, in the Newcastle aHUS cohort, there are several families with a C3 change suspected of precipitating disease. To date, mouse models of aHUS have focused on altering factor $\mathrm{H}$. To test the mechanisms behind $\mathrm{C} 3$ changes and disease, we hypothesized that a single amino acid change in C3 found in man, like D1115N, when transferred to mouse C3 would result in aHUS or aHUS-like disease.

Using recombinant mouse $\mathrm{C} 3$ and a $\mathrm{D} 1115 \mathrm{~N}$ point mutant (among others), we established that $\mathrm{C}^{\mathrm{D} 1115 \mathrm{~N}}$ was refractory to fluid phase breakdown and bound weakly to mouse mini-FH. A conditional knock-in mouse was commissioned. EM analysis of kidney from constitutively expressing homozygous $C 3^{\mathrm{D} 1115 \mathrm{~N}}$ mice at day 7 postpartum $(\mathrm{P} 7)$ revealed endothelial injury and wrinkling of the basement membrane, consistent with ischemia precipitated by a thrombotic microangiopathy (TMA). Histological analysis of kidney from homozygote $C 3^{\mathrm{D} 1115 \mathrm{~N}}$ mice (P28) revealed extensive capillary loop dilatation due to micro-aneurysm formation, mesangiolysis, and segmental double contour appearance of capillary walls consistent with a chronic TMA. C3 ${ }^{\mathrm{D} 1115 \mathrm{~N}}$ homozygote mice with active disease exhibit haematuria, thrombocytopenia, elevated creatinine and blood films show evidence of haemolysis. Collectively, these features demonstrate an aHUS phenotype, as found in man. Circulating plasma levels of activated C3 are higher in mice with active disease, compared to litter mate matched controls, and immunofluorescence studies have confirmed C3 deposition within the kidney which is distinct in its granular appearance (unlike that noted in mice devoid of $\mathrm{FH}$ which display a C3G-like phenotype). Furthermore, significant membrane attack complex is noted in the glomerulus of homozygous $\mathrm{C}^{\mathrm{D} 1115 \mathrm{~N}}$ mice, suggesting that $\mathrm{C} 5$ blockade could be used as an intervention in this model. These experiments are ongoing.

In conclusion, a unique mouse model of aHUS based on a single amino acid change in mouse C3 (D1115N) has been generated. It provides an ideal model to test future therapeutics designed to treat complement mediate TMA, to combine with other genetic or environmental changes and to understand the role of hyperactive complement in immune homeostasis in health and disease.

Characters 2499 (maximum 2500).

No conflict of Interest to report. 